\title{
Beyond Volume Indicators and Centralization: Toward a Broad Perspective on Policy for Improving Quality of Emergency Care
}

J eroen Postma and Teun Zuiderent-J erak

The self-archived version of this journal article is available at Linköping University Electronic Press:

http:/ / urn.kb.se/ resolve?urn=urn:nbn:se:liu:diva-138911

N.B.: When citing this work, cite the original publication.

Postma, J ., Zuiderent-J erak, T., (2017), Beyond Volume Indicators and Centralization: Toward a Broad Perspective on Policy for Improving Quality of Emergency Care, Annals of Emergency Medicine, 69(6), 689-697. https:// dx.doi.org/ 10.1016/j.annemergmed.2017.02.020

Original publication available at:

https:// dx.doi.org/ 10.1016/j.annemergmed.2017.02.020

Copyright: Elsevier

http:// www.elsevier.com/

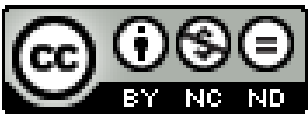




\title{
Beyond Volume Indicators and Centralization: Towards a Broad Perspective on Policy for Improving Quality of Emergency Care
}

\begin{abstract}
Study objective: Policy makers increasingly regard centralization of emergency care as a useful measure to improve quality. However, the clinical studies that are used to justify centralization, arguing that volume indicators are a good proxy for quality of care ('practice makes perfect'), have significant shortcomings. In the light of the introduction of a new centralization policy in the Netherlands, we show that the use of volume indicators in emergency care is problematic and does not do justice to the daily care provided in EDs.
\end{abstract}

Methods: We conducted an ethnographic study in three EDs, a primary care facility and an ambulance call center in the Netherlands, including 109 hours of observation, over 30 ethnographic interviews with professionals and managers and five semi-structured follow-up interviews.

Results: We argue that emergency care is a complex, multilayered practice and distinguish four different repertoires: acute and complex care, uncertain diagnostics, basic care and physical-social-mental care. A 'repertoire' entails a definition of what good care is, what professional skills are needed and how emergency care should be organized.

Conclusion: The first repertoire of acute and complex care might benefit from centralization. The other three repertoires however equally deserve attention, but are made invisible in policies that focus on the first repertoire and extrapolate the idea of centralization to emergency care as a whole. Emergency care research and policies should take all repertoires into account and pay more attention to alternative measures and indicators beyond volume, e.g. patient satisfaction, professional expertise and collaboration between EDs and other facilities.

\section{INTRODUCTION}

\section{Background}

Centralization is increasingly seen as a suitable policy instrument to improve quality, safety and efficiency of emergency care in the US and other Western health care systems. ${ }^{1,2,3}$ As a result of 
centralization, complex emergency care for ST-segment elevation myocardial infarction, stroke, major trauma and pediatric critical care, is increasingly provided in a smaller number of EDs. ${ }^{4}$ Policy makers and insurance companies stimulate further centralization by using volume indicators, which means that an ED has to perform a minimum number of treatments (a threshold) to be granted permission to perform that treatment (e.g. the Leapfrog Purchasing Principles ${ }^{5}$ ). The basic premise behind the use of volume indicators is that the more frequently health care professionals perform a certain treatment, the better the outcomes are ('practice makes perfect'). Also high-tech, expensive equipment and machines are used more efficiently.

This trend in emergency care is in line with other fields in health care where volume indicators have been driving centralization, such as oncology and cardiology. ${ }^{6,7}$ However, the evidence on the volume-quality relation in emergency care is mixed and inconclusive. Research from the UK on acute stroke services on the one hand shows that centralization in metropolitan areas is negatively correlated to mortality, length of hospital stay and cost per patient. ${ }^{3,8}$ Centralization also seems beneficial for patients with major traumas. ${ }^{1,9} \mathrm{~A}$ study on the volume/quality relation of the treatment of COPD exacerbations on the other hand suggests that high-volume EDs perform worse, perhaps as a result of ED crowding. Patients from highvolume EDs were more likely to experience early relapse or to report ongoing exacerbation. ${ }^{10}$ Another study also report a negative correlation between volume and performance, showing that high-volume EDs have longer lengths of stay, higher 'left without been seen'-rates and longer door-to-physician times. ${ }^{11}$

\section{Goals of this study}

To get a clearer picture of the (dis)advantages of centralization of emergency care, policy makers often call for more quantitative clinical studies on the relation between volume and quality. In this paper however, we problematize some assumptions that underlie volume/quality reasoning, in particular in emergency medicine, and plea for the use of qualitative research to complement the existing evidence. As an example of such an approach, we present a study of the introduction of a new policy on Dutch emergency care. The policy aims at centralization of care, based on volume indicators. By conducting interviews and observations in EDs, we gain insight in daily emergency care practices and assess whether centralization might improve quality of care. Our research question is: What constitutes good care in Emergency Departments and how does that relate to policies of centralization, such as the new policy in the Netherlands? We do not aim to provide definitive answers to this question, but hope to inspire 
a 'research for policy agenda' that combines quantitative volume/quality studies with qualitative in depth studies of emergency care, looking beyond volume indicators and centralization to improve quality of care. Before turning to the Dutch empirical case, we discuss some of the problems in volume/quality research.

\section{THE PROBLEMATIC RELATION BETWEEN VOLUME AND QUALITY}

We have stated in the introduction that the evidence on the volume/quality relation in emergency care is mixed. But there are good reasons to critically assess even the studies that suggest a clear correlation. In this section, we distinguish five reasons why volume indicators are a problematic proxy for quality of emergency care and thereby pose serious concerns as an evidence base for policy making.

\section{Many volume/quality studies have methodological problems}

A meta-analysis of systematic reviews of studies on the volume/quality relation shows that most of the studies have methodological shortcomings (e.g. they do not correct adequately for case-mix). ${ }^{12}$ As a result, the strength of the volume/outcome relation varies widely between studies. Also, studies show large differences between facilities that meet volume criteria: outliers exist across the whole spectrum of hospital and surgeon/surgical team caseload. ${ }^{12,13}$ For example, a study on Esophagectomy outcomes shows that hospitals meeting volume standards varied by a factor of five in terms of 90day mortality. ${ }^{14}$ Importantly, despite the intuitive appeal of 'practice makes perfect', the few studies that investigate whether performance improves over a longer period of time as a result of increased experience do not find a relationship between volume and quality. $^{12}$

\section{There is disproportionate attention for studies that find a positive volume/quality relation}

Due to a focus on studies that find a positive correlation between volume and outcome, studies that have failed to find this correlation are often neglected in the policy debate. There are a large number of treatments for which studies show that such a correlation is absent, including total hip arthroplasties, gynecological malignancy and major colorectal surgery. ${ }^{12}$ This does not even take into account the studies that have never been 
published as a result of 'publication bias'* in clinical research. ${ }^{15}$ Another meta-analysis of systematic reviews finds a positive volume/quality relation for only a small number of complex, high-risk treatments. ${ }^{16}$ Yet, managers and doctors use the 'volume argument' often as a justification for strategic choices of hospitals, such as merger or organizational restructuring, even when the consequences for quality of care are unknown. ${ }^{16}$

\section{Positive volume/quality relations might work the other way around ('selective referral')}

A third problem with the volume/quality relation is of statistical nature. When studies find a positive correlation, there is often no guarantee that centralization led to better quality. The causality could also work the other way around due to 'selective referral': patients are referred to facilities that have a good reputation and perform well, leading to an increase in patient volume. In that case, volume is the result of doctor and hospital performance as perceived by patients and referrers. In practice, there might be both 'practice makes perfect' and 'selective referral', but we have little insight in how the two mechanisms relate. ${ }^{17,} 18$

\section{Studies on volume/quality pay insufficient attention to the 'social fabric' of care} Fourth, there is a danger that centralization leads to quality improvement for one treatment, or on one dimension of quality, but to a loss of quality for other treatments or on other dimensions. That is, centralization of a treatment can have adverse consequences, like logistic difficulties and higher costs for parallel reorganization of associated services, that are overlooked in studies with a narrow focus on specific treatments. Also, centralization could cause longer travel distances for patients, which is an important dimension of quality in emergency situations. It is therefore important to take the 'social fabric' of care, i.e. the embeddedness of a treatment in its clinical, organizational and geographical environment, into account when assessing centralization policies. In discussions on the centralization of emergency care, this is often not the case. ${ }^{19}$

\section{Volume/quality studies tend to focus on outcomes that are easily measured}

\footnotetext{
* Publication bias means that studies with statistically significant results are more likely to be submitted and published than work with null or non-significant results.
} 
In most studies on the volume/quality relation, 30-day in-hospital mortality is used as an indicator for quality of care. ${ }^{12}$ The advantage of mortality as an outcome indicator is that it is often easily available and measurable. A disadvantage however is that it is not a good indication of quality of care for treatments of non-lethal conditions. ${ }^{20}$ Due to the focus on mortality in volume/outcome studies, alternative elements of quality are ignored, including for example quality of life for patients or patient centered care (which are more difficult to measure). The focus on outcomes that are easy to measure is not limited to volume/quality studies, but can be seen in other fields as well, for example in the development of clinical guidelines. ${ }^{21}$

\section{CASE: A NEW POLICY ON EMERGENCY CARE IN THE NETHERLANDS}

Despite the problems that are associated with volume/quality studies, they are widely used as a ground for centralization. An example is a new policy for emergency care in the Netherlands, issued by the umbrella organization for the health insurance companies that are responsible for contracting care from hospitals (Association of Health Insurers). The Association based the policy on a review of clinical studies on emergency care and proposes centralization of six acute and high-risk categories of services: severe physical trauma, acute neurology, acute cardiology, acute vascular surgery, acute obstetrics and 'other' (a list of approximately forty conditions). Each category contains a number of treatments. For example, acute neurology includes treatment of stroke, meningitis and epilepsy. For each category, the policy uses volume/quality studies on the most acute and severe conditions as a proxy for the other conditions. In the case of acute neurology, studies on stroke are used. Based on these studies, the policy prescribes a minimum number of 350 stroke patients per year for an ED. Facilities that have less stroke patients will not be reimbursed for the whole range of acute neurology. The same mechanism goes for the other categories, where a minimum number of treatments of the most acute and severe conditions is used as a proxy for the whole range of services within that category. As a result, only a small number of large hospitals that perform the threshold number of treatments would be reimbursed for the six categories of services. The policy proposes that emergency care that does not fall in one of the six categories should be delivered in thus far unspecified 'facilities for basic emergency care'.22 


\section{METHODS}

\section{Study design and setting}

To investigate the feasibility of the proposed policy in the Netherlands in relation to daily emergency care practices, and generate lessons for centralization policies in other health care systems, we carried out ethnographic research in and around EDs. By using different research methods, we ensured data triangulation. ${ }^{23}$ We conducted 109 hours of observation during a period of 10 weeks in three hospitals, 'Riverside Hospital', 'Countryside Hospital' and 'UrbanCare Hospital', a primary care facility and a regional ambulance call center (see Appendix A for more information about the fieldwork sites). The sites are representative for Dutch emergency care in terms of size and geographical location. Management of the two smaller hospitals, Riverside and Countryside, expected that they had to downgrade their ED to a basic care facility, aimed at smaller and less complex groups of patients, if the new policy would be implemented. UrbanCare would probably see an increase in the number of emergency care patients.

We conducted observations during different times of the day at each of the sites until we reached a point of saturation, i.e. additional observations did not generate new insights. The goal of the observations was to openly investigate the daily practice of emergency care and to look for what in ethnographic research are known as 'golden events'; situations that help to understand how a site works. ${ }^{24}$ During the observations, we conducted ethnographic interviews ${ }^{25}$ that lasted up to 30 minutes with over 30 medical doctors, GPs, residents, nurses, ambulance drivers, physician assistants and managers. In particular, we discussed the background/rationale behind some of the events we witnessed during the observations. In addition, we conducted five semistructured follow-up interviews ${ }^{26}$ in order to further explore some of our findings from the observations and ethnographic interviews (see Appendix A for more information about the follow-up interviews). We took field notes during the observations and ethnographic interviews, which we wrote out directly afterwards. The follow-up interviews were recorded and transcribed verbatim.

\section{Analysis}

We analyzed our material inductively ${ }^{27}$ in three rounds. First, we looked at the different types of patients that entered the EDs. Second, we analyzed the way professionals dealt 
with those different patients. Third, we looked at the organizational processes and structures that were in place to provide care to patients. We did not take the three analytical steps sequentially and only after our empirical research, but went back and forth during the research process to confirm and challenge the patterns that emerged from our findings. Based on this process, we identified four repertoires of emergency care. The Oxford English Dictionary defines a repertoire as "a stock or range of regularly performed or easily exhibited skills, techniques, abilities, etc.; a collection of typical features". Just as the performance of an artist depends on the skills that he/she possesses and exhibits in a given arena, emergency care professionals adapt their medical and organizational skills to a certain context and the needs of patients. The use of the repertoire metaphor therefore allows us to analyze the work that professionals perform in relation to the organizational setting, the characteristics of patients and their idea of what 'good care' is. We validated the four repertoires through member check $^{23}$ with the respondents in the three EDs, who confirmed that the four repertoires are representative of their work. Respondents also indicated that most patients do not fit neatly in one of the categories, but can often be placed in several categories or go from the one category to the other when the initial diagnosis changes. We therefore present the repertoires not as a blueprint, but as a heuristic for developing a broad policy perspective on emergency care.

\section{RESULTS}

In this section, we discuss four repertoires of emergency care (table 1). For each repertoire, we describe an illustrative situation that we encountered during our observations and explored further through ethnographic and semi-structured interviews. Although one repertoire is dominant in each of the situations, elements of other repertoires can be recognized as well. This illustrates the complex and layered character of emergency care.

\section{[Table 1]}

Repertoire 1: Acute and complex care 
The first repertoire comprises the acute and complex care that features prominently in the new policy of the Association of Health Insurers. Good quality of care in this repertoire is defined in clinical terms, for example mortality rate after a myocardial infarction. Out of the four repertoires, this is the repertoire we observed the least in the smaller hospitals in our study (Riverside and Countryside). During our observations at the ambulance call center, we noticed that acute and complex cases were usually referred to one of the larger hospitals in the region, where specialized medical doctors and technological infrastructure that are necessary for adequate treatment are available, and not to EDs in small hospitals. However, also small hospitals sometimes have to deal with acute and complex cases. Some patients have to be stabilized at the nearest facility before they can be transferred to a larger, more specialized facility. Other patients come to the ED with complaints that turn out to be more serious than initially thought.

\section{Riverside Hospital: Small ED in an urban area.}

The phone rings at the desk of the ED. Sandra*, the secretary, answers the phone and hears a man calling from a car, saying that he is coming in with his almost two-year-old daughter. The little girl is limp and has respiratory problems. Sandra looks for information about the girl in her electronic patient file and finds that she came to the ED two weeks ago with the same complaints. The girl was then given antibiotics and sent home. Sandra says to Bart, the coordinating emergency care nurse, that the girl is on the way and that she expects it to be nothing serious this time either. A few minutes later a car stops in front of the ED. The father jumps out of the car, lifts his daughter from the back seat and runs through the door. The mother of the girl climbs behind the wheel and parks the car.

Sandra and two other emergency care nurses bring the little girl and her father straight to the examination room, leaving the few patients already waiting with lower urgency scores to the other professionals. Soon, it does turn out to be something serious and the girl is transferred to a children's treatment room. The girl cries and moans constantly and has a dangerously low oxygen saturation. She is very pale and keeps fainting or falling

\footnotetext{
* The names of the professionals are fictional
} 
asleep. Tom, a resident, goes straight to the treatment room while Bart calls a pediatrician. The pediatrician arrives shortly because he was still in the hospital. A little while later a woman in leisurely clothing comes into the ED, throws down her coat and goes straight to the treatment room. It turns out to be a second, more experienced pediatrician who was also called.

After an intense time the child is stabilized and admitted to the pediatrics department at the hospital. One of the emergency care nurses says: "A little while ago, when we worked with the same team and the same pediatrician, we had a child that stopped breathing. That's why everything ran smoothly now: everyone knew what to do, but also where to find pediatric needles, oxygen masks et cetera."

In order to provide good care in the first repertoire, professionals at the ED work together as a team where everyone does his or her specialized task. Nurses escort patients (and often ambulance personnel) directly after they arrive to a treatment room, prepare equipment and hand out tools to residents and medical doctors. The latter perform the treatment, predominantly aimed at stabilizing patients. The more complex the case, the more rapidly specialized medical doctors are brought in and the more high-tech instruments are used. As the above case illustrates, 'practice makes perfect': experience and routines are very important. During the first minutes after arrival at the $E D$, the pace is fast and all other patients that have less urgent conditions have to wait. After patients in this repertoire are stabilized, they are usually admitted in the hospital, often at the intensive care unit, or transferred to a larger, more specialized hospital.

\section{Repertoire 2: Uncertain diagnostics}

The second repertoire comprises patients with symptoms that are hard to classify at first sight. Sometimes these patients come to the ED by themselves; at other times they are brought in by ambulance. The complaints of these patients do not immediately lead to a diagnosis; for example, in the case of a patient who is short of breath and has a slight deviation on the ECG. Like a resident stated with regard to such a patient he just admitted: "there's something funny about this patient, we just don't trust it". Another category comprises patients with chronic diseases that have a potential relapse; for 
example, a patient with a chronic heart condition and a slight chest pain. The first step in dealing with these patients is making sure they are not in immediate danger, which would lead to repertoire one. Next they are diagnosed and treated at the ED, often by a medical specialist. When this is done, sometimes after several hours, patients are usually admitted in the hospital. Good quality of care in repertoire two is predominantly defined by the speed with which a patient is diagnosed, treated and admitted and the way initial uncertainty is communicated with a patient and other health care professionals.

\section{Countryside Hospital: Small ED in a rural area.}

A man walks in the ED together with his wife and approaches the desk. He is sent in by a GP and says he has a severe abdominal pain. Mandy, an emergency care nurse, walks with the man to a treatment room. Five minutes later also Michelle, a resident, goes to the treatment room. After fifteen minutes Michelle comes back to the desk and starts a discussion with resident Greg and nurse Sylvia about the use of morphine. Michelle says that the patient scored an eight out of ten on the pain scale and that she gave him 10 milligrams of morphine. Greg and Sylvia both say that they do not like to give morphine in these situations; they have had better results with other painkillers. A few minutes later nurse Mandy returns to the desk and says that the morphine does not work: "no wonder with such a body" (the patient is obese).

Michelle decides to wait with prescribing other painkillers until the results from laboratory tests that she requested are there. Meanwhile she enters the symptoms of the patient in the electronic patient file, making use of the protocol 'acute abdominal pain'. Michelle says that she suspects that the patient has acute pancreatitis. She also says that the patient told her that he drinks about 2.5 liters of beer a day. Her diagnosis seems to be confirmed by the results from the laboratory that appear on her screen about an hour later. She subsequently calls Jeff, a surgeon. This is necessary because the GP that sent in the patient explicitly asked for the opinion of a surgeon. Michelle suspects that Jeff will confirm her diagnosis and will refer the patient to the internal medicine department. However, after Michelle discusses the symptoms of the patient and the results from the laboratory, Jeff thinks that it is not pancreatitis and says that he will come to the ED to examine the patient. In the meantime, Michelle orders a CT-scan on the request of Jeff. 
She is still convinced that the patient suffers from pancreatitis and grumbles to me about the fact that Jeff does not believe her.

After a short while Jeff comes in and goes to see the patient in the treatment room together with Michelle. When they come back to the desk, Jeff says that he thinks it is pancreatitis after all. He phones a doctor from the internal medicine department and after a short conversation gives the phone to Michelle. He asks her to pass on all the relevant information and to make sure that the patient is admitted in the hospital. Fifteen minutes later a nurse comes in and brings the patient to the internal medicine department.

Professional work in the second repertoire means dealing with uncertainty. Nurses, residents and medical doctors have to come up with a diagnosis quickly, but may also need to alter their initial diagnoses after unexpected results from the laboratory or changes in symptoms. Professionals need to have broad medical and social knowledge to assess varied and complex symptoms and communicate well with patients (e.g. for reassurance and to provide information) and colleagues (e.g. about conflicting diagnoses). Knowledge of the medical background of patients is very useful in this process. Nurses and residents also need to know what they can do by themselves and when it is time to consult a medical specialist. Good collaboration with other departments is crucial to admit patients in the hospital after they are treated at the ED. Doing so minimizes waiting time and frees up capacity for new patients.

\section{Repertoire 3: Basic care}

The third repertoire includes patients that have minor conditions, can be helped relatively easily and go home quickly after treatment. Typical examples we encountered were patients with a sports injury, like a sprained ankle, or patients with a rarer but medically still basic care need, like having a fishhook stuck deep in their finger. These patients often come to the ED by themselves. Some of them are diagnosed and then redirected to primary care facilities; others are treated in the hospital. In UrbanCare Hospital, the large hospital in our study, collaboration between emergency care and primary care was largely absent. As a consequence, 'easy' patients were treated at the 
$E D$, which sometimes led to frustration among professionals who found this a waste of time and capacity. In Riverside and Countryside Hospital, collaboration between the ED and the primary care facilities was good, with nurses as gatekeepers that decided in which facility a patient should be treated.

\section{Riverside Hospital: Small ED in a urban area.}

Two parents walk up to the desk. At the arm of the mother sits their five-year-old daughter who is weeping loudly. "We were so scared", says the mother. "We had a big mirror standing against the wall that we still had to put up. The thing weighs no less than 35 kilos. I never thought Maria could pull it over". However, Maria managed to do exactly that and the mirror fell into pieces on her head and back. She is covered with little cuts. Lisa, the secretary, brings the family to the examination room where nurse Fatima immediately joins them. Fatima looks at the cuts and sees that there is still glass in some of them. Every time she touches Maria, the child cries loudly. Fatima asks some questions that are in the mandatory diagnostic protocol, but does not finish the protocol to make sure that Maria can quickly go to the treatment room.

Paul, another nurse, explains later that the protocol is primarily used as a guideline and that there can always be reasons to treat a patient with more urgency than is strictly medically necessary. Nurses use this discretion that the system provides in situations like this: "If possible, we prioritize the treatment of children. Also pain relief is prioritized".

The third repertoire comprises care that is non-acute and non-complex, but that can have quite an impact on patients. They are scared at times and not sure how to act. In the third repertoire, professionals have to perform basic medical tasks, but they must also be able to communicate well with patients: sometimes referring them to another facility, comforting them if necessary and informing them if they have to wait for other patients that are treated with more urgency. Usually low-tech medical equipment and basic medical skills suffice, although professionals have to have diagnostic competences to rule out potentially graver conditions. Quality of care comprises good medical outcomes - which is usually the easy part - short waiting times and patient friendly communication. Professionals realize that what is minor harm for themselves can be a real drama for patients (and their parents in case of children). 


\section{Repertoire 4: Physical-mental-social care}

The fourth repertoire comprises patients with a combination of physical, psychological and social issues who often only have a minor medical condition, but have nowhere else to go than the ED. An example is an elderly woman with multiple chronic conditions, who does not have family or friends, and is brought to the ED with very high blood sugar levels. Professionals at EDs are reluctant to send such patients home after treatment when they know there is no or insufficient home care available. However, they also know that there is often no medical reason to keep the patients at the hospital. This sometimes poses ethical dilemmas.

\section{Riverside Hospital: Small ED in an urban area.}

On a Saturday afternoon, Wendy, an emergency nurse, and Soraya, a resident, stand in a corner of the ED talking. Wendy's shift is already over, but she wanted to talk to Soraya about a patient, an elderly man, who came in the night before. The patient was sent in by his GP and was examined at the ED by Soraya. Although the patient wasn't feeling well, Soraya decided that his condition was medically not serious enough to justify admission in the hospital. She sent the man home, although the nurses did not agree. They thought that the patient was very vulnerable and weak. Moreover, they saw that his wife and daughter had trouble handling the situation. "But that is not what we are for", Soraya had said to the nurses, pointing at the risk that if the patient had to be admitted, it could lead to a long stay in the hospital without a strict medical reason.

Because the resident has the final say, Wendy and the other nurses had no other option than to accept the fact that the patient was sent home. Later that night however, the patient died in his home. The nurses, especially Wendy, felt horrible about that. "Of course it is terrible for the patient, but I find it the worst for his wife and daughter. I really wish this situation would have gone differently. They already were in such terrible shape." Soraya however insists that at that time there was no medical reason to keep the patient in the hospital. She tells Wendy that she will call the family to express her condolences and that she regrets the whole situation, but that there was no other option. 
Professional work in the fourth repertoire primarily entails setting good diagnoses, providing adequate medical treatment (which can be quite difficult as the example shows) and organizing care. The latter requires cooperation between EDs and home care, nursing homes, primary care, mental care, patients and patients' families to prevent that patients who cannot stay at the hospital are left out in the cold. Countryside Hospital belongs to a 'care group' that also includes a home care organization and nursing homes, which made it easy to organize continuity of care. This mediated the risk of patients returning to an unsafe home environment. In Riverside Hospital however, patients were often sent home without additional care or admitted to the hospital, where they sometimes resided for a considerable amount of time because there was no other place they could go. In the absence of good collaboration with long-term care institutions, dealing with these multi-problem patients is challenging for ED professionals. Professionals have to be empathic, but also be clear to patients and relatives about the limits of the care they can provide in the hospital. Furthermore, they have to distinguish medical from psychosocial complaints and act accordingly by either referring patients to other facilities or admitting them in the hospital.

\section{LIMITATIONS}

This study has several limitations. First, we chose fieldwork sites that are typical for Dutch emergency care in terms of size and geographical location, but we do not know whether the sites are completely representative. Despite the fact that we saw the four repertoires in all of the EDs, contextual factors could have influenced the types of repertoire seen. Second, our analysis is based on the perspective of professionals and managers. We observed how patients reacted to the emergency care they received, but have not asked them directly about their experiences. Third, by investigating in depth what is going on in EDs, and deducing what would happen in a situation of further centralization in the Netherlands, we provide recommendations for research and policy. We can however not predict with certainty what the consequences of centralization would be. This study merely points to the risks of centralizing emergency care based on a narrow and insufficiently empirically grounded understanding of it.

\section{DISCUSSION}


The analysis shows that emergency care is a multi-layered practice where various types of care repertoires co-exist and overlap. Although patients do not always fit neatly in one repertoire, the distinction in four ideal-types provides an analytical tool for researchers and policy makers to better understand emergency care. Each repertoire entails different perspectives on 'good care', the 'good professional' and the 'good organization', showing that improving emergency care requires a variety of instruments and interventions. The proposed new policy in the Netherlands is one-sided as it is based on too narrow a definition of emergency care - only paying attention to the first repertoire - and has its evidence base almost exclusively in volume/quality studies, which we have shown to face inherent limitations. Although the details of our findings are particular to the Dutch context, the underlying mechanisms in each of the repertoires can probably be identified in other health care systems as well. Given the importance of the volume/quality relationship in debates internationally, we advice also policy makers in others settings to take the warnings this study generates into account.

Earlier studies on stroke and trauma services have shown that volume might be a good proxy for quality in complex and acute situations. ${ }^{1,3,8,9}$ For these types of care, that make up the first repertoire and are predominantly provided in large hospitals, centralization could lead to quality improvement. However, if policy attention is only geared to the repertoire of acute and complex care, possibilities for improving quality of care in the other three repertoires are left unexplored. Furthermore, this study indicates that centralization might even have negative, unintended consequences for patients in these repertoires, since the requirements for providing good emergency care within the three repertoires are sometimes at odds. For example, centralization may lead to highly specialized professionals who do not have a broad enough scope to deal with complex diagnostics (repertoire 2), to crowding and longer waiting times for non-complex patients (repertoire 3) and to insufficient attention for the coordination of care for multiproblem patients (repertoire 4). Neglecting the three non-acute and-complex repertoires, and the potential unintended consequences of centralization, might also hinder efficiency gains in the organization of emergency care. For example, without efforts to strengthen ties with long-term care providers and general practitioners, treating patients in the repertoires of basic care and physical-mental-social care continues to lead to inappropriate utilization of EDs. 
This study does not generate ready-to-use recommendations for an alternative organization of emergency care. It aims to open up current policy discussions by showing that emergency care is more diverse than policy makers often think and provides directions to improve quality of care in other ways than just centralization. First, it calls for a broad research agenda to support emergency care policies ${ }^{28}$ : a combination of quantitative outcome-oriented studies and in depth qualitative analyses of the daily practice of emergency care. Among other things, qualitative studies could focus on processes of 'selective referral' versus 'practice makes perfect' and on the 'social fabric' of emergency care, i.e. the clinical, financial and organizational impact of centralization of emergency services on other types of care. Also, future studies could validate the four repertoires in a larger number of hospitals, preferably internationally, and study the repertoires from the perspective of patients. Second, our analysis suggests that volumedriven centralization is at best a crude measure for improving quality of emergency care. Future studies and policies could take into account literature that yields a much broader perspective on quality improvement, for example training clinical staff in a broad range of skills, improving regional collaboration between healthcare providers and integrating EDs and primary care facilities. ${ }^{29,} 30$ These studies could also pay attention to the unintended consequences of centralization on the whole of emergency care, so also on the non-acute and-complex repertoires. Third, this study calls for the use of a variety of quality indicators, in addition to mortality that is dominant now but is mainly suitable for the repertoire of acute and complex care. Potential structure, process and outcome indicators include patient satisfaction, waiting and travel time, availability of medical specialists, collaboration between EDs and other facilities and the presence of 'flex tracks' and 'fast tracks' for low-complex patients. ${ }^{31}$ Such broadening of the perspective on quality improvement, seems promising to help develop more nuanced policies that are sensitive to the diversity of emergency care.

\section{REFERENCES}

1. Ten Duis HJ, Van der Werken C. Trauma care systems in The Netherlands. Injury. 2003;34:722727.

2. Institute Of Medicine. IOM report: the future of emergency care in the United States health system. Academic Emergency Medicine. 2006;13:1081. 
3. Hunter RM, Rudd DC, Thompson A, et al. Impact on clinical and cost outcomes of a centralized approach to acute stroke care in London: a comparative effectiveness before and after model. PloS one. 2013;8:70420.

4. Wang HE, Yealy DM. Distribution of specialized care centers in the United States. Annals of emergency medicine. 2012;60:632-637.

5. Leapfrog. Purchasing Principles. Available at:

http://www.leapfroggroup.org/employers_purchasers/purchasing_principles. Accessed November 30, 2015.

6. Wouters MWJM., Karim-Kos HE, Le Cessie S, et al. Centralization of esophageal cancer surgery: does it improve clinical outcome?. Annals of surgical oncology. 2009;16:1789-1798.

7. Karthikesalingam A, Hinchliffe R, Poloniecki J, et al. Centralization harnessing volumeoutcome relationships in vascular surgery and aortic aneurysm care should not focus solely on threshold operative caseload. Vascular and endovascular surgery. 2010;44:556.

8. Morris S, Hunter RM, Ramsay Al, et al. Impact of centralising acute stroke services in English metropolitan areas on mortality and length of hospital stay: difference-in-differences analysis. BMJ. 2014;349:4757.

9. Chiara O, Cimbanassi S. Organized trauma care: does volume matter and do trauma centers save lives? Current Opinion in Critical Care. 2003;9:510-514.

10. Tsai CL, Rowe BH, Cydulka RK, et al. ED visit volume and quality of care in acute exacerbations of chronic obstructive pulmonary disease. The American Journal of Emergency Medicine. 2009;27:1040-1049.

11. Welch SJ, Augustine JJ, Dong L, et al. Volume-related differences in emergency department performance. The Joint Commission Journal on Quality and Patient Safety. 2012;38:395-395.

12. Harrison A. Assessing the relationship between volume and outcome in hospital services: implications for service centralization. Health Services Management Research. 2012;25:1-6. 13. Halm EA, Lee $C$, Chassin MR. Is volume related to outcome in health care? A systematic review and methodologic critique of the literature. Annals of internal medicine. 2002;137:511520.

14. Varghese TK, Wood DE, Farjah F, et al. (2011). Variation in esophagectomy outcomes in hospitals meeting Leapfrog volume outcome standards. The Annals of thoracic surgery. 2011;91:1003-1010.

15. Easterbrook PJ, Gopalan R, Berlin JA ,et al. (1991). Publication bias in clinical research. The Lancet. 1991;337:867-872. 
16. Zuiderent-Jerak J, Kool T, Rademakers J. De relatie tussen volume en kwaliteit van zorg; Tijd voor een brede benadering (The relation between volume and quality of care; Time for a broad perspective). Utrecht/Nijmegen/Rotterdam: Consortium Onderzoek Kwaliteit van Zorg; 2012. 17. Luft HS, Hunt SS, Maerki SC. The volume-outcome relationship: practice-makes-perfect or selective-referral patterns? Health services research. 1987;22:157.

18. Dudley RA, Johansen KL, Brand R, et al. Selective referral to high-volume hospitals: estimating potentially avoidable deaths. The Journal of the American Medical Association. 2000;283:1159-1166.

19. Yudkin J. Rigorous science is needed to justify the centralisation of services. BMJ. 2014;doi:http://dx.doi.org/10.1136/bmj.g4324.

20. Glanville J, Duffy S, Mahon, J, et al. Impact of hospital treatment volumes on patient outcomes. York: York Health Economics Consortium, University of York; 2010:1-21.

21. Zuiderent-Jerak, TF, Forland, F. MacBeth, F. Guidelines should reflect all knowledge, not just clinical trials. British Medical Journal. 2012;345:e6702.

22. Association of Health Insurers (Zorgverzekeraars Nederland). Kwaliteitsvisie Spoedeisende Zorg (Vision on Quality of Emergency Care), Utrecht: Zorgverzekeraars Nederland; 2013.

23. Mays N, Pope C. Assessing quality in qualitative research. BMJ. 2000;320:50-52.

24. Lévi-Strauss, C, Anthropologie Structurale. Paris: Plon; 1958.

25. Spradley JP. The etnographic interview. Forth Worth: Harcourt Brace Javonovich College Publishers; 1979.

26. Legard R, Keegan J, Ward K. In-depth interviews. In Ritchie J, Lewis J. eds. Qualitative Research Practice. London: Sage; 2003: 138-169.

27. Dey I. Qualitative Data Analysis. London: Routledge; 1993.

28. Savage J. Ethnography and health care. BMJ. 2000;321:1400-1402.

29. McCormack RP, Hoffman LF, Norman M, et al. Voices of homeless alcoholics who frequent Bellevue Hospital: a qualitative study. Annals of Emergency Medicine. 2015;65:178-186.

30. Olthuis G, Prins C, Smits MJ, et al. Matters of concern: a qualitative study of emergency care from the perspective of patients. Annals of Emergency Medicine. 2014;63:311-319.

31. Laker LF, Froehle CM, Lindsell CJ, et al. The flex track: flexible partitioning between low-and high-acuity areas of an emergency department. Annals of Emergency Medicine. 2014;64:591603. 
Table 1. Repertoires of emergency care

\begin{tabular}{|c|c|c|c|c|}
\hline Repertoire & Patients' conditions & Quality of care & Professional skills & Organization of care \\
\hline $\begin{array}{l}\text { 1. Acute and } \\
\text { complex care }\end{array}$ & $\begin{array}{l}\text { Acute danger of } \\
\text { death or major } \\
\text { health damage }\end{array}$ & $\begin{array}{l}\text { Defined in clinical } \\
\text { terms, e.g. mortality }\end{array}$ & $\begin{array}{l}\text { Expert knowledge and } \\
\text { routines aimed at } \\
\text { achieving optimal } \\
\text { clinical outcomes }\end{array}$ & $\begin{array}{l}\text { Standardized teamwork } \\
\text { in high-tech facilities }\end{array}$ \\
\hline $\begin{array}{l}\text { 2. Uncertain } \\
\text { diagnostics }\end{array}$ & $\begin{array}{l}\text { Symptoms that are } \\
\text { hard to classify or } \\
\text { relapses in a } \\
\text { chronic disease, } \\
\text { often leading to } \\
\text { hospital admission }\end{array}$ & $\begin{array}{l}\text { Speed of diagnosis, } \\
\text { treatment and } \\
\text { admission and clear } \\
\text { communication with } \\
\text { patients in uncertain } \\
\text { situations }\end{array}$ & $\begin{array}{l}\text { Excellent diagnostic and } \\
\text { communicative skills } \\
\text { and knowledge of the } \\
\text { background and medical } \\
\text { history of patients }\end{array}$ & $\begin{array}{l}\text { Presence of a wide } \\
\text { range of diagnostic } \\
\text { tools and good } \\
\text { collaboration between } \\
\text { the emergency } \\
\text { department and other } \\
\text { hospital departments }\end{array}$ \\
\hline 3. Basic care & Minor health issues & $\begin{array}{l}\text { Short waiting times } \\
\text { and patient friendly } \\
\text { communication }\end{array}$ & $\begin{array}{l}\text { Routine medical skills, } \\
\text { good planning and } \\
\text { communicative skills }\end{array}$ & $\begin{array}{l}\text { Collaboration between } \\
\text { the emergency } \\
\text { department and primary } \\
\text { care facilities }\end{array}$ \\
\hline $\begin{array}{l}\text { 4. Physical- } \\
\text { mental-social } \\
\text { care }\end{array}$ & $\begin{array}{l}\text { Multi-problems } \\
\text { (medical- } \\
\text { psychological- } \\
\text { social) }\end{array}$ & $\begin{array}{l}\text { Good diagnosis, clear } \\
\text { communication with } \\
\text { patients and well- } \\
\text { organized (long-term) } \\
\text { care }\end{array}$ & $\begin{array}{l}\text { Good organizing skills, } \\
\text { empathy, good } \\
\text { diagnostic and } \\
\text { communicative skills, } \\
\text { knowledge of other } \\
\text { (long-term) social and } \\
\text { medical services }\end{array}$ & $\begin{array}{l}\text { Collaboration between } \\
\text { the emergency } \\
\text { department and home } \\
\text { care, nursing homes, } \\
\text { mental care and primary } \\
\text { care facilities }\end{array}$ \\
\hline
\end{tabular}




\section{APPENDIX A}

\section{Fieldwork sites}

\begin{tabular}{|l|l|l|}
\hline Name & $\begin{array}{l}\text { Hours of } \\
\text { observation }\end{array}$ & Characteristics \\
\hline Riverside Hospital & 25 & $\begin{array}{l}250 \text { beds; located in an urban area; ED combined with a primary } \\
\text { care facility; ED closed at night time (between 10 PM and 8 AM); } \\
\text { emergency physician present during the day (between 8 AM and } \\
6 \text { PM) }\end{array}$ \\
\hline $\begin{array}{l}\text { Countryside } \\
\text { Hospital }\end{array}$ & 40 & $\begin{array}{l}300 \text { beds; located in a rural area; primary care facility in the } \\
\text { proximity; ED open 24 hours a day; emergency physician present } \\
\text { during the day (between 8 AM and 6 PM) }\end{array}$ \\
\hline UrbanCare Hospital & 20 & $\begin{array}{l}450 \text { beds; located in an urban area; ED with a primary care } \\
\text { facility in the proximity; ED open 24 hours a day; fulltime } \\
\text { emergency physician presence }\end{array}$ \\
\hline Primary care facility & 12 & $\begin{array}{l}\text { Located in the proximity of Countryside Hospital; open from 5 } \\
\text { PM until 8 AM, in weekends and on holidays; GP present to } \\
\text { provide basic emergency care }\end{array}$ \\
\hline Ambulance call \\
center & 12 & $\begin{array}{l}\text { Located in the region of Countryside Hospital; 24 hours a day } \\
\text { operational for emergency calls; responsible for ambulance } \\
\text { coordination }\end{array}$ \\
\hline
\end{tabular}

${ }^{1}$ In the Netherlands, it is (still) not mandatory to have an emergency physician present in the ED. That is changing, but particularly small EDs are until now run by part-time emergency physicians and residents who have back-up from attendings outside office hours.

\section{Respondents of semi-structured interviews}

\begin{tabular}{|l|l|l|}
\hline Job title & Length of interview & Personal characteristics \\
\hline ED-physician & 61 minutes & Female, 35 years old, works at the ED for 6 six months \\
\hline ED-nurse & 55 minutes & Female, 37 years old, works at the ED for almost 10 years \\
\hline ED-manager & 61 minutes & $\begin{array}{l}\text { Male, 45 years old, background as a nurse, works at the } \\
\text { ED for almost 2 years }\end{array}$ \\
\hline ED-secretary & 36 minutes & Female, 50 years old, works at the ED for 2 years \\
\hline Resident & 51 minutes & Male, 28 years old, second year resident \\
\hline
\end{tabular}




\section{Topic list semi-structured interviews}

- Professional background of the respondent

- Content of the work at the ED

- Types of patients that enter the ED

- Difficult situations at the ED

- Ideas about quality of emergency care

- Professional skills that are required at the ED

- Collaboration with other departments in the hospital and external health care providers 